\title{
Design of Single-Sided Linear Induction Motor (SLIM) for Magnetic Levitation Railway Transportation
}

\author{
Min Min Oo \\ Department of Electrical Power Engineering, Technological University, Banmaw, Myanmar \\ Email address: \\ drminminoo.tub $a$ gmail.com
}

\section{To cite this article:}

Min Min Oo. Design of Single-Sided Linear Induction Motor (SLIM) for Magnetic Levitation Railway Transportation. International Journal of Systems Science and Applied Mathematics. Vol. 3, No. 1, 2018, pp. 1-9. doi: 10.11648/j.ijssam.20180301.11

Received: June 3, 2018; Accepted: June 19, 2018; Published: July 10, 2018

\begin{abstract}
This paper studies Single-sided linear induction motor (SLIM) which can be used to motivate in a levitation railway transportation system. The rotary motor is cut out and laid flat to form the equivalent linear induction motor. Linear induction motors (LIM) are used in many different applications, from slow moving sliding doors to high-speed trains around the world. The primary goal is to analyze a small laboratory sized single-sided linear induction motor (SLIM) for educational aid. This research describes the design and construction of the $100 \mathrm{~W}$ rating stator component of a SLIM. SLIM consists of stator and rotor. The stator can supply $20 \mathrm{~V}$ and $5 \mathrm{~A}$. It is built with iron laminations; having 6 poles and wound with a double layer type. The rotor is coated with aluminum and attached with six permanent magnets. This rotor is located on top of the aluminum track. A SLIM model of specified parameters is designed using a user-interactive MATLAB program. The performance curves of the SLIM i.e., thrust and efficiency, are drawn and then analyzed for target thrust and different rated slips. The effect of parameters of the SLIM such as air-gap, thickness of permanent magnet and the number of poles on the performance of SLIM are analyzed and the results are also discussed.
\end{abstract}

Keywords: Single-Sided Linear Induction Motor (SLIM), Stator, Rotor, Magnetic Levitation, Permanent Magnet

\section{Introduction}

Linear motors potentially have unlimited applications. Linear induction motors (LIM) alone have found application in the following general areas: conveyor systems, material handling and storage, people movers, liquid metal pumping, accelerators and launchers, machine tool operation, airport baggage handling, opening and closing drapes, operation of sliding doors and low and medium speed trains. For low speed applications both flat and tubular linear induction motors (TLIM) are suitable. The single-sided linear induction motor is by far the most widely used linear motor.

A flat or single-sided LIM i.e., a SLIM, is obtained by the imaginary process of "cutting" and "unrolling" a rotary induction motor. In practice, the primary or stator of a LIM consists of a rectangular slotted structure (E type) formed by a stack of steel laminations. Within the slots of the primary stack are laid the poly phase windings to produce the linearly traveling magnetic field, just like the rotating magnetic field in a rotary induction motor, produced by the poly phase stator windings. The secondary of the LIM, or rotor, which is an permanent magnet (or electromagnet), completes the magnetic circuit and creates the magnetic flux linkage across the air gap. This in turn induces a voltage on the conductive wall, which generates an eddy current in the conducting outer layer of the secondary. The interaction between the eddy current and the changing electromagnetic field generates electromagnetic thrust on the plate in the longitudinal direction of the motor [1-2].

\section{Linear Induction Motor Configuration}

A flat or single-sided LIM i.e., a SLIM, is obtained by the imaginary process of "cutting" and "unrolling" a rotary induction motor. In practice, the primary or stator of a LIM consists of a rectangular slotted structure (E type) formed by a stack of steel laminations. Within the slots of the primary stack are laid the poly phase windings to produce the linearly traveling magnetic field, just like the rotating magnetic field in a rotary induction motor, produced by the poly phase stator 
windings.

The secondary of the LIM, or rotor, which is an permanent magnet (or electromagnet), completes the magnetic circuit and creates the magnetic flux linkage across the air gap. This in turn induces a voltage on the conductive wall, which generates an eddy current in the conducting outer layer of the secondary. The interaction between the eddy current and the changing electromagnetic field generates electromagnetic thrust on the plate in the longitudinal direction of the motor [1-4].

Induction machine operates on the same principle as the conventional rotary motor. The rotary motor is cut out and laid flat to form the equivalent LIM. Nothing has changed, only the direction of motion has changed. A linear induction motor is basically a rotating squirrel cage induction motor opened out flat, as shown in Figure 1. Instead of producing rotary torque from a cylindrical machine it produces linear force from a flat one. Depending on the size and ratings of the LIM, they can produce thrust up to several thousands newtons. The speed of the LIM is determined by the winding design and supply frequency.

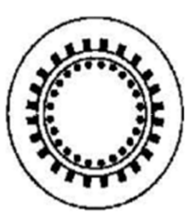

(a) Conventional Motor

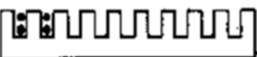

(b) Linear Motor
Figure 1. Imaginary Process of Obtaining a LIM from its Rotary Counterpart [19].

\section{Design Procedure}

\subsection{Stator Design}

The stator design is limited to the available laminations, stator length and number of poles. These are the laminations that were purchased at the time for this project as shown in Figure 2. Figure 3 displays the dimensions of the laminations; each lamination is $0.6 \mathrm{~mm}$ thick [5-10].

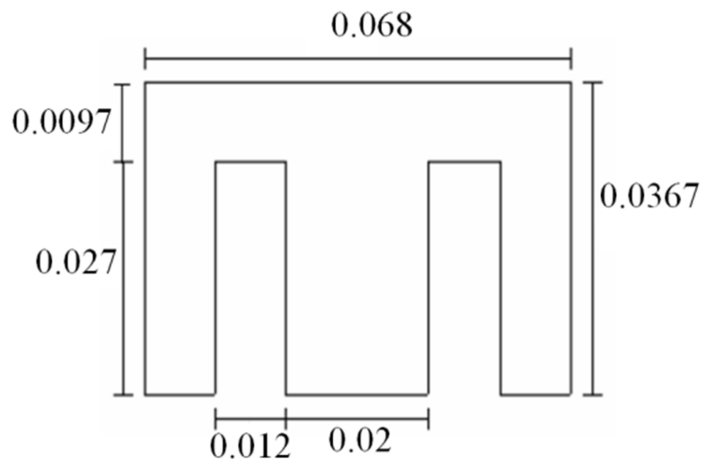

Figure 2. A Single Lamination.

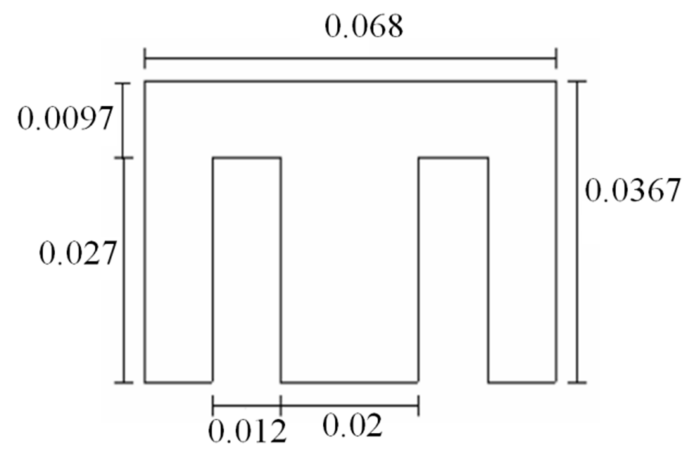

Figure 3. Dimensions of Single Lamination (m).

The stator length cannot be any longer than $0.533 \mathrm{~m}$. Each piece of lamination thick is $0.0002 \mathrm{~m}$, about 2340 laminations place side by side to one another makes up a total length of 0.5 $\mathrm{m}(0.0002 \times 2340)$. To keep the stator construction symmetrical and to increase strength, the next layer will be arranged in the opposite layout of the previous layer. There are a total of 2340 lamination sheets available for construction. With this arrangement, 2340 laminations contribute to 130 layers. The width of the stator is $0.08 \mathrm{~m}$ excluding the glue that holds it together ( $7 \mathrm{~mm}$ glue). Each layer is glued together with an adhesive spray. Once 130 layers are filled up on the jig with glue, they are compressed firmly to ensure an even distribution of glue. Any glue squeezed out through the sides is cleaned with a cloth. Finally the 18 sets of 130 layers are glued together and compressed as shown in Figure 4.

For linear movement along the stator, the rotor needs to be attached to wheels for guidance. The wheels must be of adjustable height, so that the air gap distance can be varied for various experiments. The wheels must be strong enough to withstand any lateral forces produced.

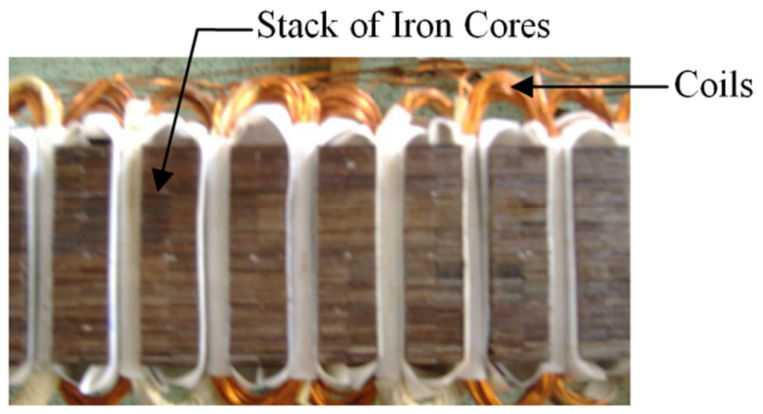

Figure 4. 2340 Layers of Stator.

For this project, SLIM might contain six poles along its length and be wound with one slots/pole/phase. This linear induction motor would have a total of 18 coils for the three phases as shown in Figure 5. There are three alternatives to connect these coils [11]:

(i) Each 6 coils in series to form the one set of group

(ii) All total 18 coils in series to form the three sets of groups

(iii) Three sets of groups in star connection

When LIM is designed, the designer aims for maximum economical flux density. Short primary LIM tends to favor series connections; this is to avoid any over-heating of the 
coils nearest to the ends of the machine. While short secondary LIM generally prefers the parallel connections, to enable a reasonable working flux density in the active section. The stator will be supplied with 3-phases star connection, due to the simplicity of the circuit connection. A connection with delta configuration will require wires running externally around the stator to join up each phase.

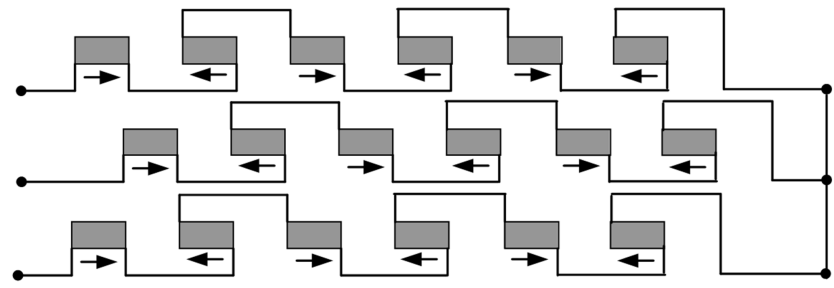

Figure 5. All Total 18 Coils of Groups in Star Connection.

\subsection{Reaction Plate Design}

The reaction plate design can consist of either a solid or laminated design.

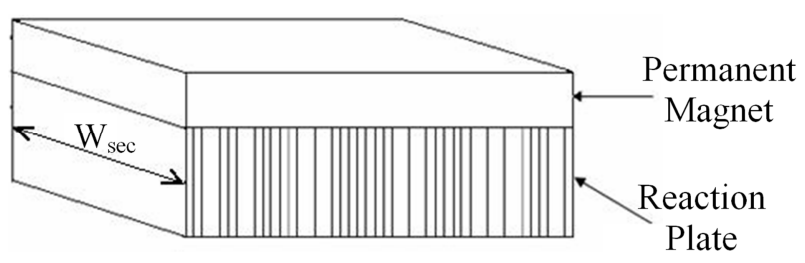

Figure 6. Secondary [19].

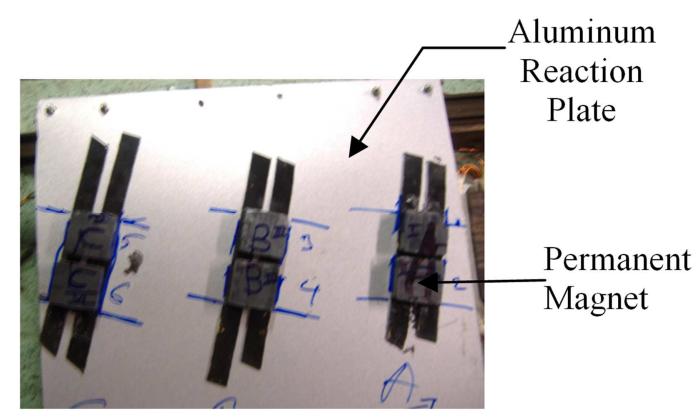

Figure 7. Permanent Magnets with Reaction Plate.
To improve performance, the reaction plate is coated with a conduction sheet of either aluminum or copper as shown in Figure 6 and Figure 7. In a SLIM configuration, the secondary component is an important segment of the LIM magnetic circuit. The SLIM performance is greatly degraded if the reaction plate is solid instead of laminations. With laminated reaction plate, the eddy current carried by the laminations and the resulting ohmic losses, and the thrust are both small enough to be ignored. The amount of thrust produced by the SLIM will depend on the permeability of the reaction plate; lower permeability will result in lower thrust and poor power factor. Different materials will be used as the reaction plate to test exactly how this affects the amount of thrust produced.

For standard operation, the reaction plate should not be any less than $2 \mathrm{~mm}$ thick. The attached permanent magnet should not be any less than $6 \mathrm{~mm}$ thick. The best thrust /size ration is obtained when the width of the secondary is related to the core width.

$$
\mathrm{W}_{\mathrm{sec}}=\mathrm{W}_{\mathrm{s}}+\frac{2 \tau}{\pi}
$$

Where;

$$
\begin{aligned}
& \mathrm{W}_{\text {sec }}=\text { width of secondary } \\
& \mathrm{W}_{\mathrm{s}}=\text { width of stator } \\
& \mathrm{T}=\text { pole pitch }
\end{aligned}
$$

The width for the reaction plate $=\mathrm{W}_{\mathrm{s}}+2 \tau / \pi$

$$
\begin{aligned}
& =0.08 \mathrm{~m}(+7 \mathrm{~mm} \text { for glue })+2 \times 0.089 \mathrm{~m} / \pi \\
& =0.14 \mathrm{~m}
\end{aligned}
$$

Laminations are used to prevent any unwanted and wasteful induction action taking place between the primary winding and the reaction plate of the magnetic circuit. Figure 7 illustrates the possible laminations arrangements. For any given direction of flux there are two planes in which the reaction plate can be laminated, and one which cannot. It would be expensive and time consuming to build two separate reaction plates with the possible laminations arrangements. The reaction plate will either be laminated in either the first or second option.

Table 1. Design Parameters of SLIM at 10\% Slip, Target Thrust 40N

\begin{tabular}{llll}
\hline No & Description & Symbol & Design 1 (20V) \\
\hline 1 & Slots per pole per phase & $\mathrm{q}_{1}$ & 1 \\
2 & Yoke flux density (tesla) & $\mathrm{B}_{\text {ymax }}$ & 0.4 \\
3 & Tooth flux density (tesla) & $\mathrm{B}_{\text {tmax }}$ & 0.6 \\
4 & Core width (m) & $\mathrm{W}_{\mathrm{s}}$ \\
5 & Electrical frequency $(\mathrm{Hz})$ & $\mathrm{f}$ \\
6 & Air gap (m) & $\mathrm{g}$ \\
7 & SLIM synchronous velocity $(\mathrm{m} / \mathrm{s})$ & $\mathrm{V}_{\mathrm{s}}$ \\
8 & Rotor velocity (m) & $\mathrm{V}_{\mathrm{r}}$ \\
9 & No. of poles & $\mathrm{p}$ \\
10 & Pole pitch (m) & $\tau$ \\
11 & Slot pitch (m) & $\lambda$ \\
12 & Stator Length (m) & $\mathrm{L}_{\mathrm{s}}$ \\
13 & "Target" thrust (N) & $\mathrm{F}_{\mathrm{s}}^{\prime}$ \\
14 & Number of turns per slot & $\mathrm{N}_{\mathrm{c}}$ \\
15 & Number of turns per phase & $\mathrm{N}_{1}$ \\
16 & Copper wire size in winding & - \\
\hline
\end{tabular}




\begin{tabular}{llll}
\hline No & Description & Symbol & Design 1 (20V) \\
\hline 18 & Slot width $(\mathrm{m})$ & $\mathrm{w}_{\mathrm{s}}$ & 0.012 \\
19 & Tooth width $(\mathrm{m})$ & $\mathrm{W}_{\mathrm{t}}$ & 0.02 \\
20 & Minimum tooth width $(\mathrm{m})$ & $\mathrm{w}_{\mathrm{t} \text { tmin }}$ & 0.0068 \\
21 & Slot depth $(\mathrm{m})$ & $\mathrm{h}_{\mathrm{s}}$ & 0.027 \\
22 & Stator core yoke height $(\mathrm{m})$ & $\mathrm{h}_{\mathrm{y}}$ & 0.0097 \\
23 & Actual thrust at specified $\mathrm{V}_{\mathrm{r}}(\mathrm{N})$ & $\mathrm{F}_{\mathrm{s}}$ & 40.698 \\
24 & Output power at specified $\mathrm{V}_{\mathrm{r}}(\mathrm{kW})$ & $\mathrm{P}_{\text {out }}$ & 162.793 \\
25 & Input power at specified $\mathrm{V}_{\mathrm{r}}(\mathrm{kW})$ & $\mathrm{P}_{\text {in }}$ & 203.126 \\
26 & Stator efficiency at specified $\mathrm{V}_{\mathrm{r}}(\%)$ & $\mathrm{\eta}$ & 80.1 \\
27 & Actual rated stator RMS current $(\mathrm{A})$ & $\mathrm{I}_{1}$ & 17.1 \\
28 & Actual stator current density $\left(\mathrm{A} / \mathrm{mm}^{2}\right)$ & $\mathrm{J}_{1}$ & 5.65 \\
29 & Area of slot $\left.(\mathrm{cm})^{2}\right)$ & $\mathrm{A}_{\mathrm{s}}$ & 0.629 \\
30 & Total area of wire $\left.(\mathrm{cm})^{2}\right)$ & $\mathrm{A}_{\mathrm{wt}}$ & 0.0245 \\
31 & Total length of copper wire $\left(\mathrm{cm}{ }^{2}\right)$ & $\mathrm{T}_{\mathrm{lw}}$ & 11.15 \\
32 & Total weight of copper wire $(\mathrm{kg})$ & $\mathrm{W}_{\text {copper }}$ & 0.24 \\
33 & Weight of iron core $(\mathrm{kg})$ & $\mathrm{W}_{\text {iron }}$ & 9.2 \\
34 & Total weight of one SLIM stator $(\mathrm{kg})$ & $\mathrm{W}_{\text {stator }}$ & 9.44 \\
\hline
\end{tabular}

\subsection{Complete SLIM Design}

The input power supply terminal, stator and reaction place can now be assembled together to produce a complete SLIM design as shown in Figure 8. As the reaction plate moves along the length of the stator, the power supply coil must be long enough and properly mounted. Since the frequency is fixed at $25 \mathrm{~Hz}$, an adjustable frequency drive is required for precise variable speed control of the motor. To prevent the motor from over shooting the travel length, limit switches are attached to each ends of the reaction plate. These are triggered to turn the machine off when they are activated.

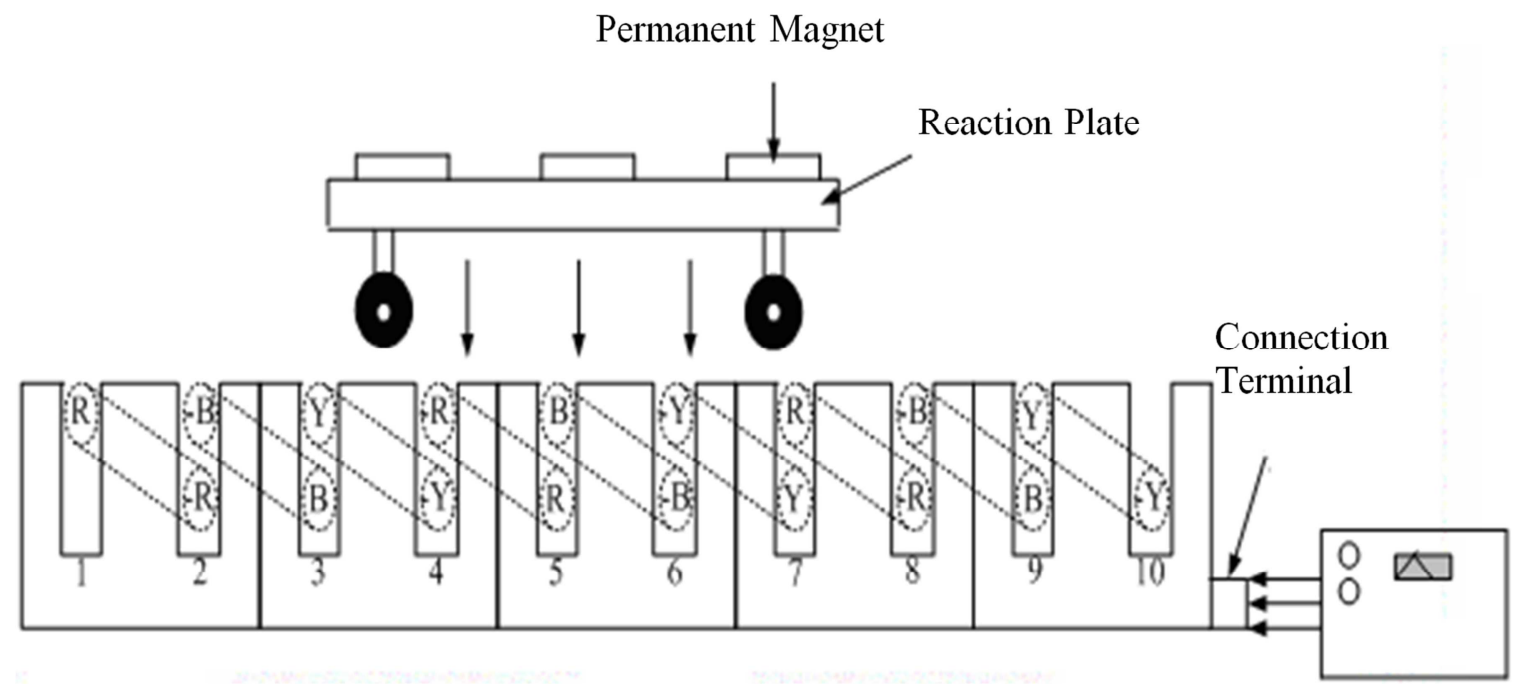

Figure 8. Complete Design of SLIM.

\section{Performance Curves}

Once the design parameters were obtained, the performance of the SLIM stator as a function of rotor velocity, are evaluated as shown in the following figures. The performance curves of the SLIM, thrust $F_{s}$ and efficiency $\eta$ as a function of rotor velocity $\mathrm{V}_{\mathrm{r}}$, at a rated slip of $5 \%$ to $10 \%$ and a target thrust of $40 \mathrm{~N}$ are as shown in Figure 9 and Figure 10 using the results from Table 2. As the rated slip of SLIM is increased, the magnitude of thrust force and efficiency also increases. So, the value of rated slip $10 \%$ is chosen as the best value which yields maximum thrust at a reasonable efficiency. The efficiency does not have significant impact with an increase in rated slip $9 \%$ and $10 \%$. The best design of the SLIM at a rated slip of $10 \%$ and a desired speed of $40 \mathrm{~N}$ is shown in Table 1. Using these results, the variation of thrust $F_{s}$ and efficiency $\eta$ with respect to rotor velocity $\mathrm{V}_{\mathrm{r}}$ are shown in Table 2 .

In order to sketch the characteristic curves of the SLIM, the following procedure is followed. The slip is varied from 0 to 1 in increments of 0.0001 and the unit impedance of the stator is calculated as a function of slip using the Equation 2.

$$
Z=R_{1}+j X_{1}+\frac{j\left(\frac{R_{2}}{S} X_{m}\right)}{\frac{R_{2}}{S}+j X_{m}}
$$




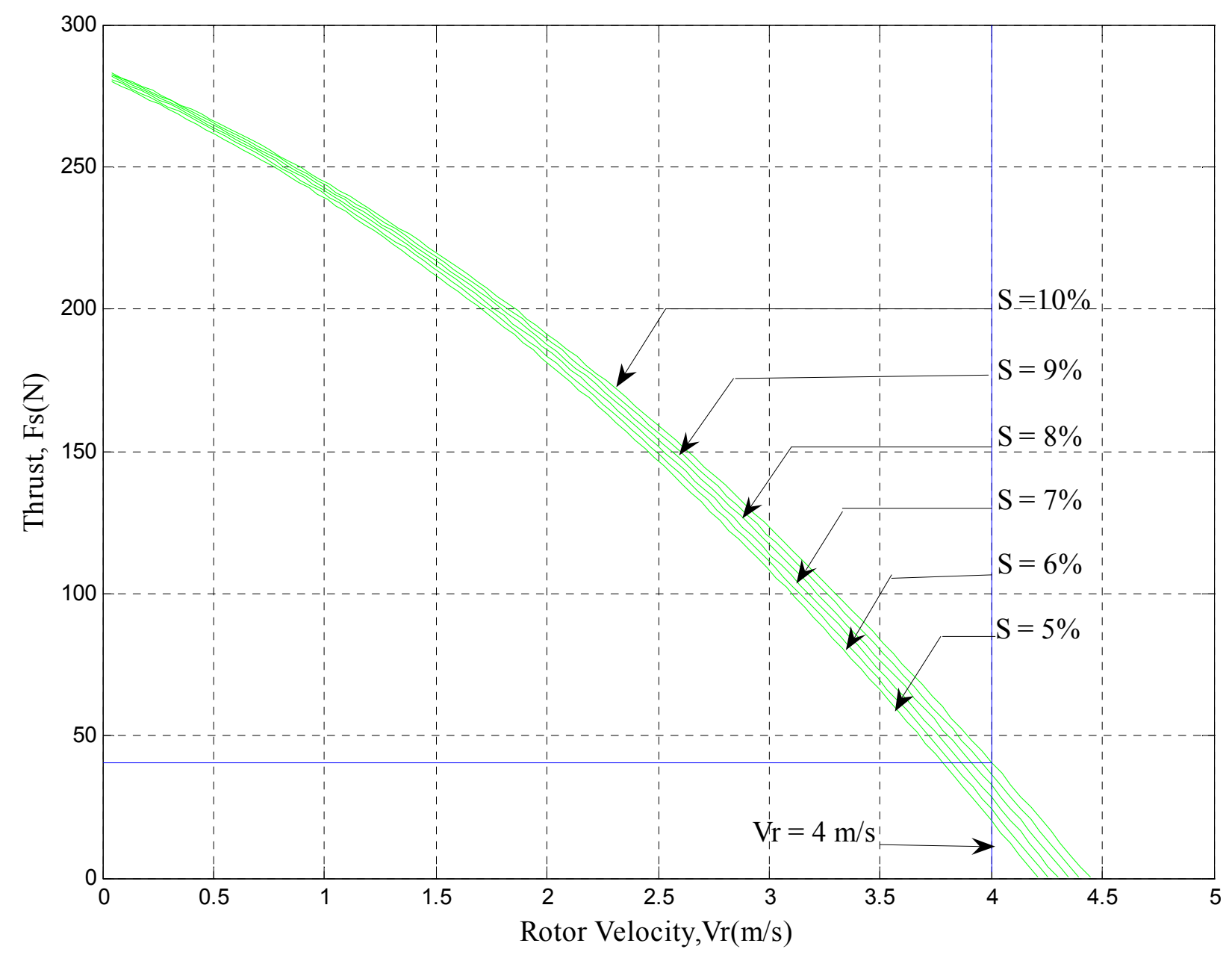

Figure 9. Effect of Rated Slip on the Thrust $F_{s}$ and Rotor Velocity $V_{r}$ of One SLIM Stator Unit, a Desired Rotor Velocity of $4 \mathrm{~m} / \mathrm{s}$, a Target Thrust of $40 \mathrm{~N}$.

Table 2. Rated Slip Effects on Thrust and Efficiency.

\begin{tabular}{lll}
\hline Rated Slip, S (\%) & Thrust, $\mathbf{F}_{\mathbf{s}} \mathbf{( N )}$ & Efficiency, $\boldsymbol{\eta}$ (\%) \\
\hline 5 & 20.066 & 76.32 \\
6 & 24.166 & 78.15 \\
7 & 28.284 & 79.26 \\
8 & 32.415 & 79.87 \\
9 & 36.554 & 80.14 \\
10 & 40.698 & 80.14 \\
\hline
\end{tabular}

The actual SLIM stator RMS current is then calculated using the Equation 3.

$$
I_{1}=\frac{V_{1}}{|Z|}
$$

The resulting thrust is then calculated using Equation 4 as

$$
\mathrm{F}_{\mathrm{s}}=\frac{\mathrm{mI}_{1}^{2} \mathrm{R}_{2}}{\left[\frac{1}{(\mathrm{SG})^{2}}+1\right] \mathrm{V}_{\mathrm{s}} \mathrm{S}}
$$

The performance curves, thrust and efficiency are then plotted versus varying rotor speed $\mathrm{V}_{\mathrm{r}}$ as shown in Figure 11 . 


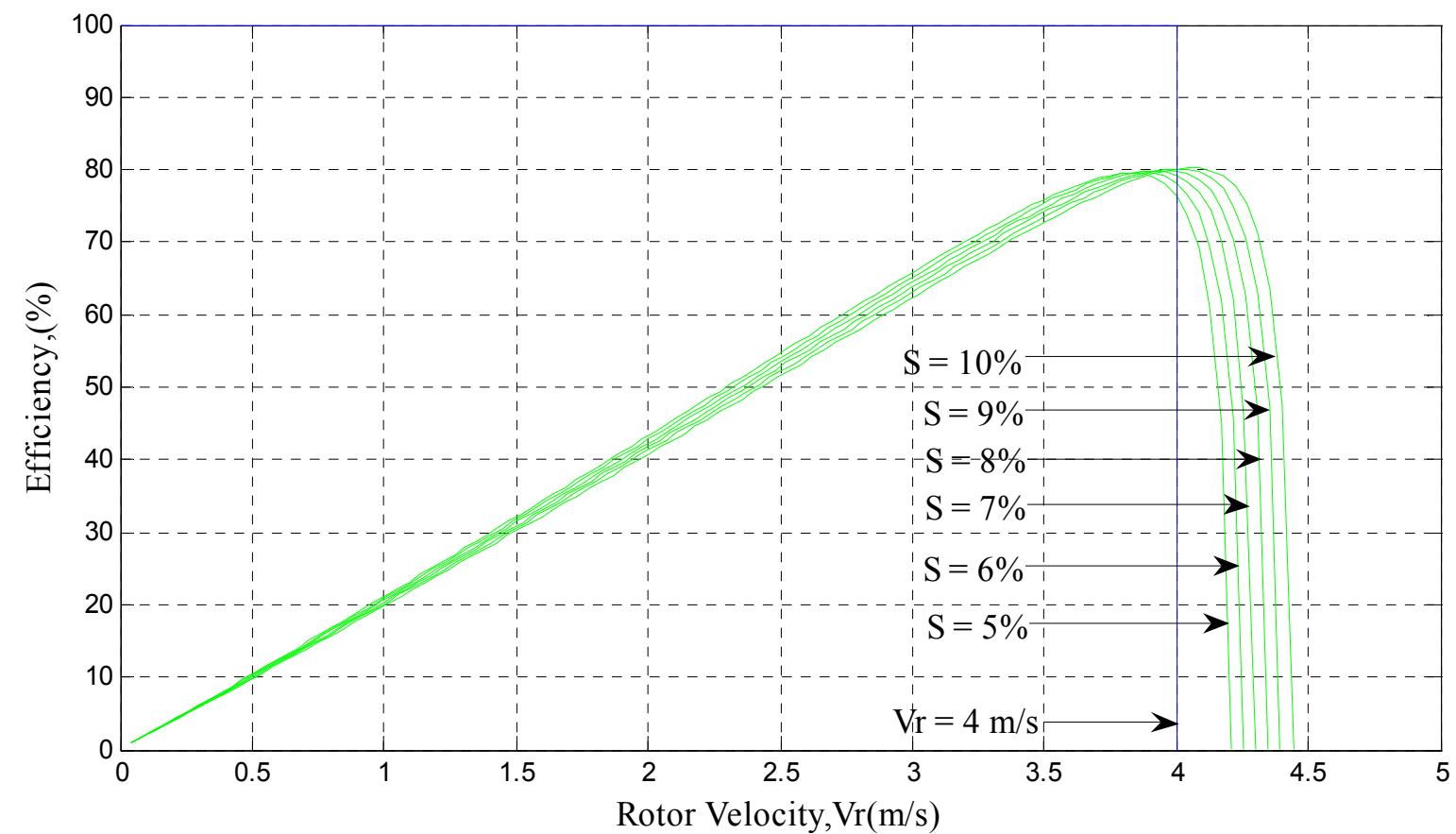

Figure 10. Effect of Rated Slip on Efficiency $\eta$ and Rotor Velocity $V_{r}$ of One SLIM Stator Unit, a Desired Rotor Velocity of $4 \mathrm{~m} / \mathrm{s}$, a Target Thrust of $40 \mathrm{~N}$.

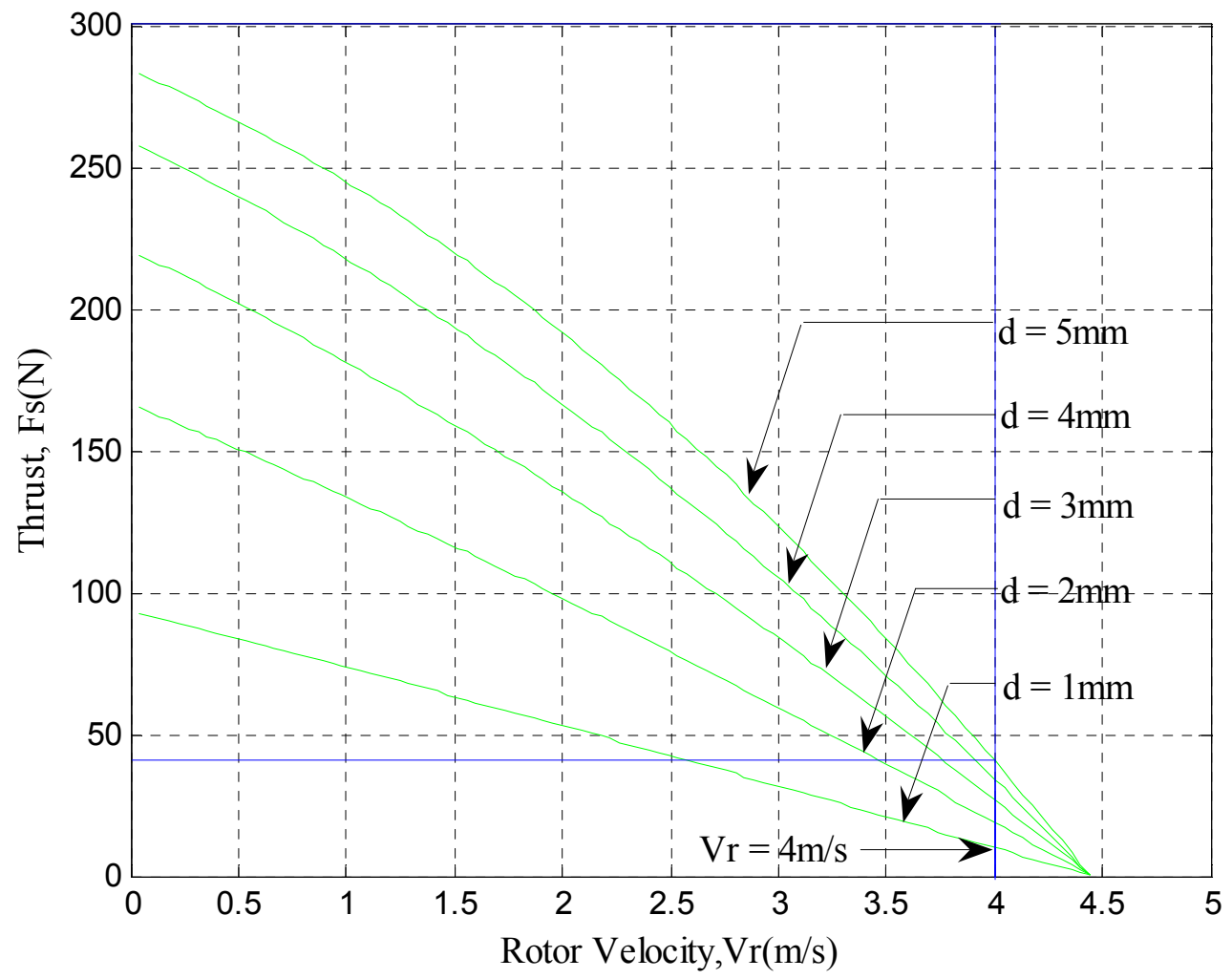

Figure 11. Effect of Permanent Magnet Thickness on the Thrust of SLIM plotted against Rotor Velocity at a Rated Slip of 10\%, a Desired Rotor Velocity of 4 $\mathrm{m} / \mathrm{s}$ and Target Thrust of $40 \mathrm{~N}$.

Table 3. Permanent Magnet Thickness Effects on Thrust and Efficiency at Rated Rotor Speed (4 m/s).

\begin{tabular}{lll}
\hline Permanent Magnet Thickness, $\mathbf{d}(\mathbf{m m})$ & Thrust $\mathbf{F}_{\mathbf{s}} \mathbf{( N )}$ & Efficiency $\boldsymbol{\eta}(\mathbf{\%})$ \\
\hline 1 & 9.897 & 77.3 \\
2 & 18.837 & 80 \\
3 & 26.9 & 80.5 \\
4 & 34.164 & 80.4 \\
5 & 40.698 & 80.1 \\
\hline
\end{tabular}




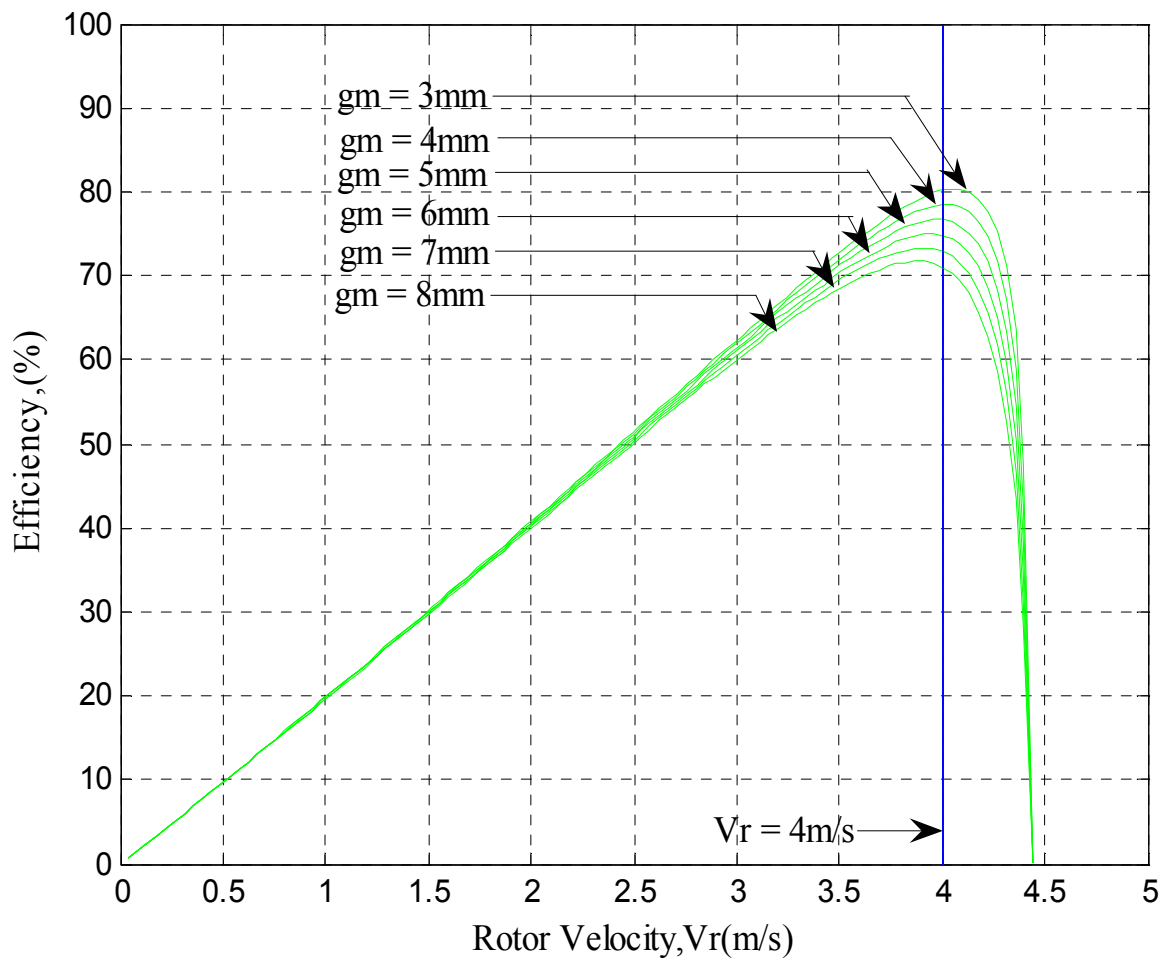

Figure 12. Effect of Varying Permanent Magnet Thickness on Efficiency of SLIM plotted against Rotor Velocity at a Rated Slip of 10\%, a Desired Rotor Velocity of $4 \mathrm{~m} / \mathrm{s}$ and Target Thrust of $40 \mathrm{~N}$.

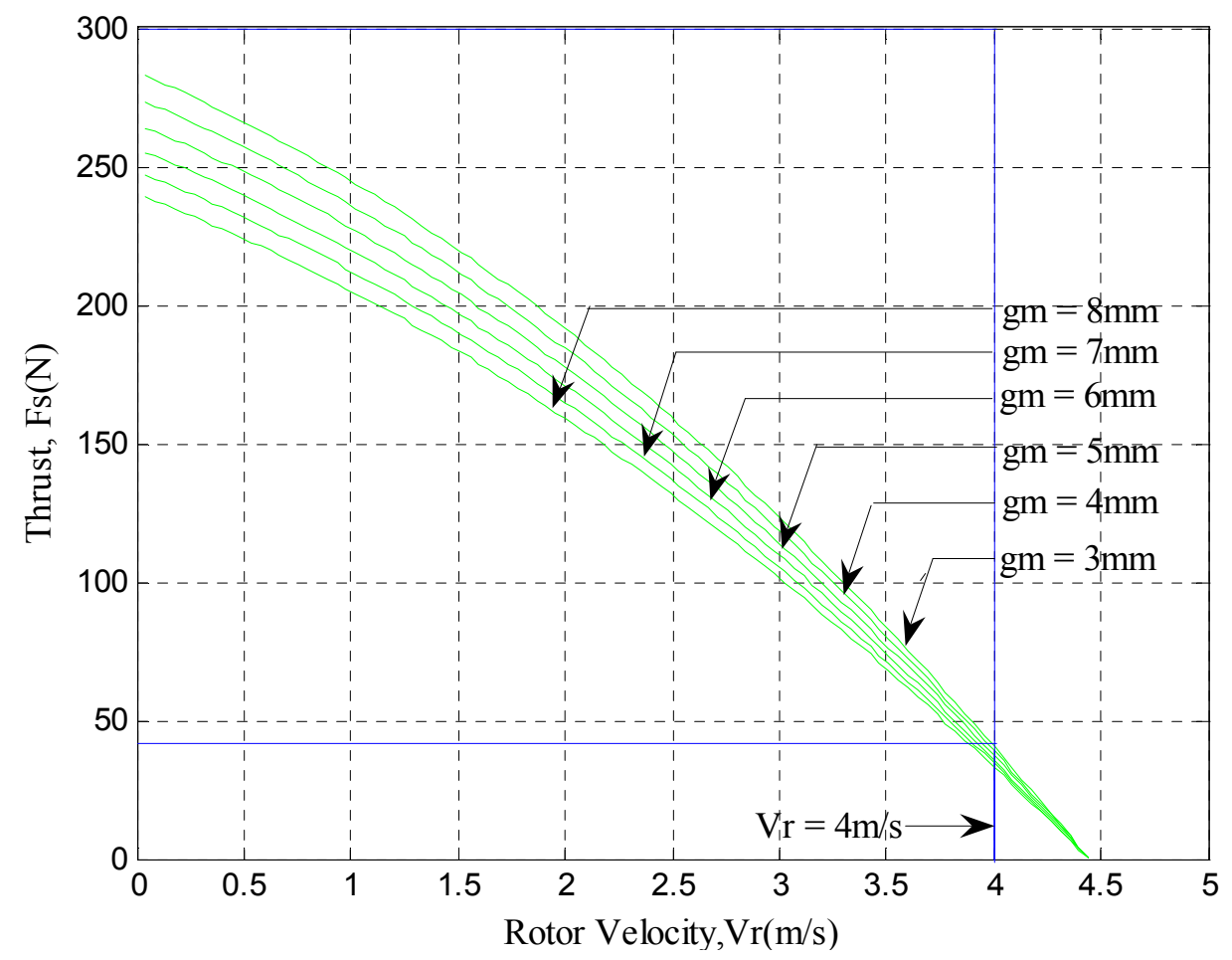

Figure 13. Effect of Mechanical Air-Gap on Thrust of SLIM at a Rated Slip of $10 \%$ and a Target Thrust of $40 \mathrm{~N}$.

Table 4. Air-Gap Effects on Thrust and Efficiency.

\begin{tabular}{lll}
\hline Air-Gap, $\mathbf{g}_{\mathbf{m}}(\mathbf{m m})$ & Thrust $\mathbf{F}_{\mathbf{s}}(\mathbf{N})$ & Efficiency $\boldsymbol{\eta} \mathbf{( \% )}$ \\
\hline 3 & 40.698 & 80.1 \\
4 & 39.017 & 78.4 \\
5 & 37.42 & 76.6 \\
6 & 35.904 & 74.8 \\
\hline
\end{tabular}




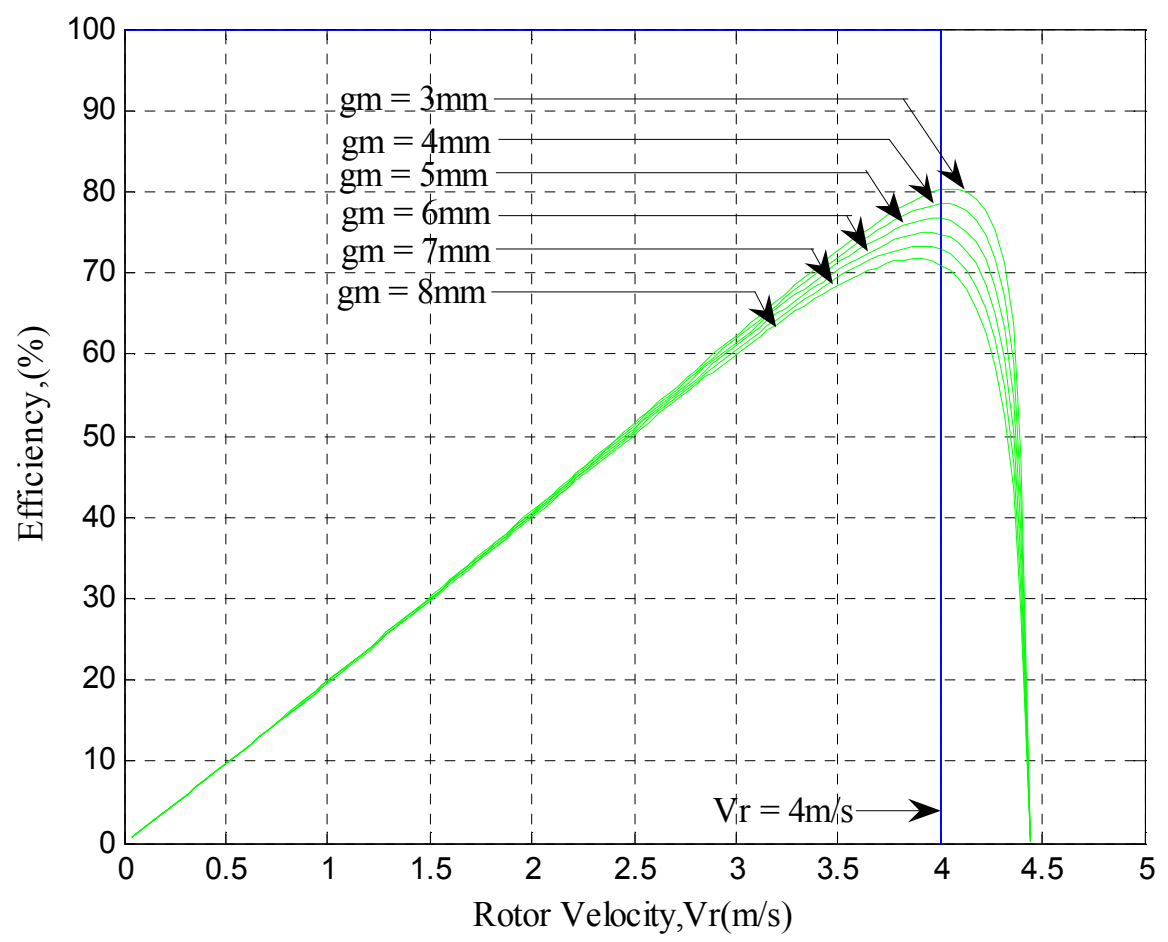

Figure 14. Effect of Magnetic Air-Gap on the Efficiency of a SLIM versus Rated Rotor Velocity.

\section{Conclusion}

In this paper, the theoretical model is focused on the linear induction motor. When the design of the physically model is well known, this information is applied for the design and the operating point of the control system. The air-gap plays a very important role in the performance of the SLIM. The airgap needs to be as small as possible to have a better thrust and efficiency. Another crucial design parameter is the thickness of rotor outer layer which is permanent magnets. As the thickness of the permanent magnet is increased thrust also increases along with the length of magnetic air-gap which is undesirable. The regenerative model was not studied in this paper. This is an important issue because the technology was studied in ascent mode (as a linear motor), but in the descent mode it needs to work as levitation and more speeds should by stored. The study of the levitation mode was not performed because the goal and scope of the thesis was the modeling and validation of the model for a single-sided linear induction motor based on the levitation technology. The single-sided linear induction motor was chosen only as an application case study to show how the technology can be used and optimized. Note that, if some constraints were changed, another single-sided linear induction motor would be obtained.

\section{Acknowledgements}

The author wishes to acknowledge Dr. Myint Thein, Rector, Yangon Technological University, for his kind permission, providing encouragement and giving helpful advices and comments. Special thanks are also owed to Dr.
Myo Myint Aung, Associate Professor and Head, Department of Electrical Power Research Engineering, Mandalay Technological University, for thoroughly proofreading this paper and giving useful remark on it.

\section{References}

[1] M. H. Holakooie, M. B. Banna Sharifian, M. R. Feyzi, Sensorless Indirect Field Oriented Control of Single-Sided Linear Induction Motor With a Novel Sliding Mode MRAS Speed Estimator, International Journal of Engineering (IJE), TRANSACTIONS A: Basics Vol. 28, No. 7, (July 2015)

[2] Amir Zare Bazghaleh, Mohammad Reza Naghashan, and Mohammad Reza Meshkatoddini, "Optimum Design of Single-Sided Linear Induction Motors for Improved Motor Performance", IEEE TRANSACTIONS ON MAGNETICS, VOL. 46, NO. 11, NOVEMBER 2010.

[3] Koushik Shit, Nilanjan Maji, Dharmbir Prasad, and Rudra Pratap Singh, "DEVELOPMENT OF SINGLE-SIDED LINEAR INDUCTION MOTOR WITH ADVANCED REGENERATIVE BRAKING SYSTEM", 9th International Conference on Eelctrical Rotating Machines and Drives, 14th15th September 2017, India.

[4] A. Zare Bazghaleh, M. R. Naghashan, H. Mahmoudimanesh, M. R. Meshkatoddini, "Effective Design Parameters on the End Effect in Single-Sided Linear Induction Motors", World Academy of Science, Engineering and Technology 64, 2010.

[5] Berdut, E. Oct, 1994. Levitation and Propulsion System Using Permanent Magnets and Interleaved Iron or Steel. U.S. Patent No 5,452,633.

[6] Berdut, E. Dec. 1996. Permanent Magnet Type Automotive Vehicle Suspension. U.S. Patent No 5,584,367. 
[7] Flores, O. Jun. 2004. Analysis and Simulation of EM Fields of Permanent Magnets DC Linear Motor used to Propulse a Magnetically Levitated Train. Master Thesis. UPRM.

[8] James, E. d., Shackelford, E. d., and Alexander, F. 2001. Materials Science and Engineering Handbook. Third Edition.

[9] Torres Morales, L. A., and Serrano, D. 2003. Finite Element
Simulation of Magnetically Leviated Train Using Berdut Poles. COINAR, San Juan, PR.

[10] Gieras, J. F., and Wing, M. 2002. Permanent Magnet Motor Technology. Marcel Dekker Inc: New York.

[11] Ogilive, D. Jan. 2003. The M3 Urban Transportation System. Part of FTA Project MA-26-7077. 